\title{
Resíduos de saúde no brasil e drogas ilícitas: uma visão interdisciplinar
}

O descarte de drogas ilícitas no Brasil ocorre com impactos negativos ambientais, de saúde e de segurança. O objetivo do presente trabalho é expor o sistema jurídico-ambiental brasileiro de gestão de resíduos sólidos em geral e dos resíduos sólidos de saúde, exatamente para demonstrar o processo de disposição final ambientalmente adequado destes resíduos ou rejeitos, obtendo-se assim, um parâmetro para identificação da gravidade dos riscos ambientais inerentes ao incorreto descarte de drogas ilícitas, já que há lacuna na legislação brasileira sobre a correta disposição de resíduos gerados pelo uso de drogas legais ou ilegais pela pessoa física. Será utilizada uma abordagem sistêmica para a análise do presente tema, valendo-se da interdisciplinaridade que articule saberes do direito, da engenharia sanitária, da educação básica e da saúde, convergentes para um modelo de sustentabilidade ambiental.

Palavras-chave: Drogas Ilícitas; Descarte; Impactos; Sistema Jurídico-Ambiental Brasileiro; Gestão de Resíduos Sólidos.

\section{Health residues in Brazil and illicit drugs: an interdisciplinary view}

Disposal of illicit drugs in Brazil occurs with negative environmental impact, health and safety. The objective of this study is to expose the Brazilian legal-environmental system of solid waste management in general and solid waste from healthcare, just to show the final disposal process environmentally sound such waste or tailings, thus obtaining a parameter to identification of the severity of the risks inherent to the incorrect disposal of illicit drugs, as there is gap in the Brazilian legislation on the proper disposal of waste generated by the use of legal or illegal drugs by individuals. A systemic approach will be used for the analysis of this issue, taking advantage of interdisciplinarity that articulates the right knowledge, sanitary engineering, basic education and health, converged for an environmental sustainability model.

Keywords: Illicit drugs; Discard; Impacts; Brazilian Legal and Environmental System; Solid Waste Management.

\section{Topic: Direito Ambiental}

Reviewed anonymously in the process of blind peer.

\section{Sandro Luiz da Costa}

Universidade Federal de Sergipe, Brasil

http://lattes.cnpq.br/7416946586434951

sandrolcosta@infonet.com.br

\section{Maria José Nascimento Soares}

Universidade Federal de Sergipe, Brasil http://lattes.cnpq.br/8392706159125796 marjonaso@ufs.br

Flávia Moreira Guimarães Pessoa

Universidade Federal de Sergipe, Brasil

http://lattes.cnpq.br/2987779178843187

flaviampessoa@gmail.com
Received: 27/11/2015

Approved: 14/07/2016

\section{Referencing this:}

COSTA, S. L.; SOARES, M. J. N.; PESSOA, F. M. G.. Resíduos de saúde no brasil e drogas ilícitas: uma visão interdisciplinar. Scientiam Juris, v.4, n.1, p.6-18, 2016. DOI: http://doi.org/10.6008/SPC2318-

DOI: 10.6008/SPC2318-3039.2016.001.0001 $\underline{3039.2016 .001 .0001}$ 


\section{INTRODUÇÃO}

As drogas de efeito psicoativo, após o seu manuseio e uso, sejam para finalidades legais ou ilegais, deixam resíduos (em sentido lato) que deveriam ser descartados de forma ambientalmente correta, com a finalidade de se evitar efeitos danosos ao meio ambiente, à saúde e à segurança da população, com prejuízo da qualidade ambiental em virtude da poluição causada.

Obviamente, em relação às drogas ilícitas, não há uma preocupação do usuário sequer com o aspecto penal, ou seja, de se tratar a utilização desta ou seu descarte incorreto de uma conduta ofensiva ou que expõe a risco bens jurídicos de relevante importância para sociedade, sujeitando-o a uma sanção penal, quanto mais, com os aspectos ambientais, de saúde e segurança.

Mesmo que existisse uma preocupação ambiental por parte do usuário, a própria clandestinidade da atividade ilegal, à míngua de uma política de redução de danos, impõe que o descarte seja efetivado de forma a ocultar a materialidade e a autoria do fato, sendo, assim, executada direta ou indiretamente em corpos hídricos, no solo.

Para se constatar a potencialidade de geração de dano ambiental e contra a saúde humana ${ }^{1}$ do incorreto descarte de resíduos provenientes do uso ilícito de drogas psicotrópicas é importante que se entenda como são classificados estes resíduos quanto à sua periculosidade e como devem ser corretamente descartados os decorrentes dos serviços de saúde. Assim, é exposto o sistema jurídico-ambiental brasileiro de gestão de resíduos sólidos em geral e dos resíduos sólidos de saúde, exatamente para demonstrar o processo de disposição final ambientalmente adequado destes resíduos ou rejeitos, obtendo-se assim, um parâmetro para identificação da gravidade dos riscos ambientais inerentes ao incorreto descarte de drogas ilícitas, já que há lacuna na legislação brasileira sobre a correta disposição de resíduos gerados pelo uso de drogas legais ou ilegais pela pessoa física².

\section{METODOLOGIA}

Para tanto será necessária uma abordagem sistêmica, valendo-se da interdisciplinaridade que articule saberes do direito, da engenharia sanitária, da educação básica e da saúde, convergentes para um modelo de sustentabilidade ambiental.

\section{DISCUSSÃO TEÓRICA}

\section{Sistema Jurídico Ambiental de Resíduos Sólidos no Brasil}

O sistema infraconstitucional jurídico ambiental brasileiro de resíduos sólidos, no âmbito legislativo da União, tem como normas principais a Lei da Política Nacional do Meio Ambiente (Lei 6.938/1981), a Lei da Política Nacional de Saneamento Básico (Lei 11.445/2007), a Lei da Política Nacional de Resíduos Sólidos (Lei

\footnotetext{
${ }^{1}$ Saúde deve ser entendida como um conjunto de bem estar físico, mental e social, e não só a ausência de doenças.

${ }^{2}$ Neste sentido, mas se referindo apenas ao consumidor final de drogas legais (ALVARENGA; NICOLETTI, 2010, p. 35).
} 
12.305/2010), a Lei da Política Nacional de Educação Ambiental (Lei 9.975/1999) e a Lei das Infrações Penais e Administrativas Ambientais (Lei 9.605/1998).

A Lei da Política Nacional do Meio Ambiente (LPNMA), dentre outras importantes definições, cria o Sistema Nacional do Meio Ambiente (SISNAMA) e estabelece a obrigação de licenciamento de atividades com potencialidade de dano ambiental.

O SISNAMA é constituído, em âmbito federal por diversos órgãos e entidades, destacando-se aqui o Conselho Nacional do Meio Ambiente (CONAMA), órgão deliberativo e consultivo e o Instituto Brasileiro de Meio Ambiente e Recursos Hídricos (IBAMA), órgão executor deste sistema. O CONAMA, dentro de sua competência deliberativa, tem a importante função de estabelecer normas e padrões sobre meio ambiente no Brasil, resultando disso, centenas de resoluções que complementam o sistema jurídico ambiental brasileiro. Nesse sentido, como se verá à frente, não há como se discutir a correta gestão de resíduos de saúde, sem se observar, no mínimo, resoluções do CONAMA e da área de saúde que tratam do assunto.

O IBAMA é o órgão executor do Sistema Ambiental Nacional, tendo como funções primárias o licenciamento ambiental, o monitoramento destes licenciamentos e a fiscalização ambiental. Nos demais âmbitos federativos deveria também existir órgãos e entidades simetricamente similares à federal. Assim, no Estado de Sergipe, a Administração Estadual do Meio Ambiente (ADEMA) é o órgão executivo e o Conselho Estadual, o órgão deliberativo e consultivo do Estado.

Ressalta-se que a LPNMA define que poluição é a degradação ambiental (alteração adversa da qualidade do meio ambiente) causada pelo ser humano (pessoa jurídica ou física) (Art. 3으) e que a responsabilidade civil pelo dano ambiental é objetiva (Art. 14, §1으), independendo assim da prova do dolo ou da culpa.

A Lei da Política Nacional de Resíduos Sólidos (LPNRS), regulamentada pelo Decreto 7.404/2010, especifica a Política de Saneamento Ambiental no País em relação a resíduos sólidos, consolidando assim o sistema jurídico ambiental brasileiro de resíduos sólidos, além de definir políticas e diretrizes fundamentais para a proteção do meio ambiente, tais como a) não geração, redução, reutilização, reciclagem, tratamento dos resíduos sólidos e disposição final ambientalmente adequada dos rejeitos; b) definição de processos que busquem a alteração dos padrões de produção e consumo sustentável de produtos e serviços; c) educação ambiental; d) gestão integrada de resíduos sólidos; e) controle social; e f) planejamento estratificado nos diversos níveis federativos, alcançado responsabilidades no setor empresarial e na sociedade de consumo numa responsabilidade compartilhada.

A LPNRS define gestão integrada (sustentável) de resíduos sólidos como "[...] conjunto de ações voltadas para a busca de soluções para os resíduos sólidos, de forma a considerar as dimensões política, econômica, ambiental, cultural e social, com controle social e sob a premissa do desenvolvimento sustentável [...]" (Art. 3ㅇ, XI) e o gerenciamento destes resíduos como uma atividade mais no plano operacional, exercida “[...] nas etapas de coleta, transporte, transbordo, tratamento ${ }^{3}$ e destinação final ambientalmente adequada

${ }^{3}$ Refere-se basicamente a processos que visam à redução de volume dos resíduos. 
dos resíduos sólidos e disposição final ambientalmente adequada dos rejeitos ${ }^{4}$, de acordo com plano municipal de gestão integrada de resíduos sólidos ou com plano de gerenciamento de resíduos sólidos [...]" (Art. $3 \circ, \mathrm{X})$.

A pessoa física também pode ser considerada geradora de resíduos pela LPNRS, aplicando-se, por exemplo, a responsabilidade compartilhada ${ }^{5}$, além da responsabilidade administrativa, civil e penal por infrações ao meio ambiente (Art. 225, §3으, da CF).

Os resíduos são classificados pela LPNRS em não perigosos e perigosos, sendo estes os que tem as características de "[...] inflamabilidade, corrosividade, reatividade, toxicidade, patogenicidade, carcinogenicidade ${ }^{6}$, teratogenicidade ${ }^{7}$ e mutagenicidade ${ }^{8}$, apresentam significativo risco à saúde pública ou à qualidade ambiental, de acordo com lei, regulamento ou norma técnica [...]" (Art. 13, II, "a"). Os resíduos não perigosos são aqueles que não se enquadram no conceito de resíduos perigosos (Art. 13, II, "b").

A lei 9.605/1998 trata das infrações penais e administrativas contra o meio ambiente, tipificando penalmente a conduta de quem "[...] causar poluição de qualquer natureza em níveis tais que resultem ou possam resultar em danos à saúde humana, ou que provoquem a mortandade de animais ou a destruição significativa da flora [...]" (Art. 54), com pena de até cinco anos de reclusão e multa no tipo qualificado (art. $54, \S 2 \div)$.

De forma mais específica, a Lei 9.605/1998 tipifica o incorreto manuseio e gerenciamento de resíduos perigosos, em seu artigo $56, \S 1$ 으, sancionando tal conduta com pena privativa de liberdade (reclusão) de até quatro anos e pena de multa:

$\S 1$ 10 Nas mesmas penas incorre quem:

I - abandona os produtos ou substâncias referidos no caput ou os utiliza em desacordo com as normas ambientais ou de segurança;

II - manipula, acondiciona, armazena, coleta, transporta, reutiliza, recicla ou dá destinação final a resíduos perigosos de forma diversa da estabelecida em lei ou regulamento [...] (grifo nosso).

Para Carvalho (2011) o tipo penal previsto no Art. 56, §1으, da Lei 9.605/1998 é de fundamental importância para a

tutela do meio ambiente, da saúde dos seres humanos e dos seres vivos não humanos, haja vista que as substâncias tóxicas, de modo geral [...] tem sido responsáveis pela eliminação de várias formas de vida animal, e bem assim, vem se consolidando como um dos principais veículos de intoxicação dos seres humanos, além de uma potencial via de desencadeamento de doenças graves (CARVALHO, 2011, p. 361).

\footnotetext{
4 "Rejeitos: resíduos sólidos que, depois de esgotadas todas as possibilidades de tratamento e recuperação por processos tecnológicos disponíveis e economicamente viáveis, não apresentem outra possibilidade que não a disposição final ambientalmente adequada" (Art. 3으, XV, da LPNRS).

5 "Responsabilidade compartilhada pelo ciclo de vida dos produtos: conjunto de atribuições individualizadas e encadeadas dos fabricantes, importadores, distribuidores e comerciantes, dos consumidores e dos titulares dos serviços públicos de limpeza urbana e de manejo dos resíduos sólidos, para minimizar o volume de resíduos sólidos e rejeitos gerados, bem como para reduzir os impactos causados à saúde humana e à qualidade ambiental decorrentes do ciclo de vida dos produtos, nos termos desta Lei (art. 3ำ XVII, da LPNRS).

6 "Substâncias, misturas, agentes físicos ou biológicos cuja inalação ingestão e absorção cutânea possam desenvolver câncer ou aumentar sua frequeência. O câncer é o resultado de processo anormal, não controlado da diferenciação e proliferação celular, podendo ser iniciado por alteração mutacional" (ABNT, 2004, p. 2).

${ }^{7}$ Qualquer substância mistura, organismo, agente físico ou estado de deficiência que, estando presente durante a vida embrionária ou fetal, produz uma alteração na estrutura ou função do individuo dela resultante. (Idem).

${ }^{8}$ Qualquer substância mistura, agente físico ou biológico cuja inalação, ingestão ou absorção cutânea possa elevar as taxas espontâneas de danos ao material genético e ainda provocar ou aumentar a freqüência de defeitos genéticos. (Idem).
} 
Paralelamente e de forma cumulativa, o Decreto 6.514/2008, que regulamenta a Lei 9.605/1998, também define sanções administrativas para tais condutas, prevendo multas que podem chegar ao patamar de cinquenta milhões de reais (Art. 61, 62 e 64).

Não obstante, estas normas cogentes em múltiplas esferas, a educação ambiental é uma abordagem preventiva das mais importantes para ampliar mudanças de atitudes paradigmáticas em relação à harmonia entre o ser humano e o meio ambiente e está normatizada em nosso ordenamento por meio da Lei da Política Nacional de Educação Ambiental (LPNEA), onde incorpora o conceito constitucional de desenvolvimento sustentável do relatório Brundtland e o caráter complexo e sistêmico do meio ambiente e dos saberes ambientais, com vistas à conscientização ${ }^{9}$, percepção e sensibilização do ser humano, em processo formativo de sentir-se ser capaz de ressignificar a partir do preceito "viva de acordo com a natureza" e isto faz sentido porque nossa natureza é "normativa", vez que há dias, noites, estações, mudanças climáticas dentre outras e o que nos falta é a compreensão e por pura ignorância e ganância provocamos impactos socioambientais. Assim, a educação ambiental é uma alternativa:

por meio dos quais o indivíduo e a coletividade constroem valores sociais, conhecimentos, habilidades, atitudes e competências voltadas para a conservação do meio ambiente, bem de uso comum do povo, essencial à sadia qualidade de vida e sua sustentabilidade (Art. 1으, da LPNEA).

Nesse sentido, a LPNEA apresenta os princípios básicos da educação ambiental, destacando-se a construção multi, inter e transdisciplinar do saber no plano epistemológico, praxiológico e ontológico (FAZENDA, 2008), fazendo uso de uma abordagem teórico-metodológica com:

a) enfoque humanista, holístico, democrático e participativo;

b) concepção do meio ambiente em sua totalidade, considerando a interdependência entre o meio natural, o sócio-econômico e o cultural, sob o enfoque da sustentabilidade;

c) pluralismo de ideias e concepções pedagógicas, na perspectiva da inter, multi e transdisciplinaridade;

d) reconhecimento e o respeito à pluralidade e à diversidade individual e cultural (Art. 4으, da LPNEA).

Nessa direção, as escolas e a sociedade como um todo devem assumir o compromisso de manter a riqueza da natureza circulando em sua vida, dando sua contribuição com responsabilidade compartilhada minimizando as limitações manifestadas pela (im)potencialidade do cumprimento das bases legais em vigência.

\section{Regulamentação dos Resíduos Sólidos de Saúde no Brasil}

O sistema jurídico brasileiro aplicável a resíduos sólidos de saúde (RSS) é um subsistema do sistema jurídico brasileiro de resíduos sólidos, acima apresentado, sendo especificado, basicamente, por resoluções do CONAMA e normas técnicas da área de saúde e da engenharia. A definição do alcance e do sentido (interpretação) destas normas deve levar em consideração a inter-relação recíproca e a lógica desse sistema normativo.

\footnotetext{
${ }^{9}$ Corroborando com a concepção de Freire essa “[...] é um compromisso histórico. É também consciência histórica: é inserção crítica na história, implica que os homens assumam o papel de sujeitos que fazem e refazem o mundo. Exige que os homens criem sua existência com um material que a vida Ihes oferece" $(1979$, p. 26).
} 
A saúde é estabelecida em nossa Constituição Federal como dever do estado e direito de todos, sendo de relevância pública os serviços e ações de saúde, cabendo ao poder público regulamentar sua fiscalização e controle (Arts. 196 e 197)

Frise-se que o conceito de saúde adotado nos documentos internacionais de direitos humanos abrange desde a típica face individual do direito subjetivo à assistência médica em caso de doença, até a constatação da necessidade do direito do Estado ao desenvolvimento, personificada no direito a um nível de vida adequado a manutenção da dignidade humana (DALLARI, 2003, P. 48).

A Constituição Federal estabelece ainda no seu Art. 225, o direito ao meio ambiente ecologicamente equilibrado ${ }^{10}$ como essencial à sadia qualidade de vida da população, sendo dever da sociedade e do poder público sua preservação e recuperação, pois é reconhecido como bem de uso comum do povo cuja preservação visa a evitar conflitos entre gerações ${ }^{11}$. Desta forma, as atividades lesivas ao meio ambiente sujeitam o infrator às sanções cumulativas nas esferas administrativa, cível e penal.

\section{Os Resíduos de Serviços de Saúde (RSS) em Âmbito Federal}

A Lei 9.782/1999, que estabelece o Sistema Nacional de Vigilância Sanitária, criou a Agência Nacional de Vigilância Sanitária (ANVISA), com a função, dentre outras, normatizar os RSS por meio do (Art. 7o, IV) e ainda a Lei 10.308/2001 que dispõe sobre rejeitos radioativos e trata da competência da Comissão Nacional de Energia Nuclear (CNEN), para regulamentar sobre rejeitos radioativos.

Os RSS são de responsabilidade do gerador e por sua potencialidade significativa de dano ambiental são controlados pelo poder público em várias instâncias (plano de gerenciamento de resíduos, licenciamento ambiental, controle municipal e da ANVISA, dentre outros).

As normas que tratam da "correta" gestão de resíduos de serviços de saúde em nosso país, servem de modelo de como as drogas ilícitas deveriam ser tratadas e destinadas após seu uso em função de suas características impactantes.

A principal norma do CONAMA que trata sobre RSS é a resolução 358/2005, sincronizada com a norma RDC-306/2004 da ANVISA, sendo, ao lado da Lei da Política Nacional de Resíduos Sólidos, a principal regulamentação sobre RSS no Brasil. No campo das regras técnicas, a Associação Brasileira de Normas

\footnotetext{
${ }^{10} \mathrm{O}$ conteúdo e a extensão do âmbito de proteção do direito fundamental ao meio ambiente dependerá do paradigma ético-filosófico adotado, se relacionado com uma ética antropocêntrica, uma ética zoocêntrica, uma ética biocêntrica ou uma ética ecocêntrica. Vale dizer que diversos normativos internacionais e nacionais que versam sobre o direito ao meio ambiente não podem ser automaticamente alinhados a qualquer um deles, havendo uma ampla margem para a interpretação jurídica. A par disso, percebe-se uma franca evolução das normas jurídicas em direção a novas axiologias, afastando-se da visão antropocêntrica tradicional.

11 "Meio ambiente - Direito à preservação de sua integridade (CF, art. 225) - Prerrogativa qualificada por seu caráter de metaindividualidade - Direito de terceira geração (ou de novíssima dimensão) que consagra o postulado da solidariedade - Necessidade de impedir que a transgressão a esse direito faça irromper, no seio da coletividade, conflitos intergeneracionais - Espaços territoriais especialmente protegidos (CF, art. 225, $§ 1$ 으, III) Alteração e supressão do regime jurídico a eles pertinente - Medidas sujeitas ao princípio constitucional da reserva de lei - Supressão de vegetação em área de preservação permanente - Possibilidade de a administração pública, cumpridas as exigências legais, autorizar, licenciar ou permitir obras e/ou atividades nos espaços territoriais protegidos, desde que respeitada, quanto a estes, a integridade dos atributos justificadores do regime de proteção especial - Relações entre economia (CF, art. 3ํ, II, c/c o art. 170, VI) e ecologia (CF, art. 225) - Colisão de direitos fundamentais - Critérios de superação desse estado de tensão entre valores constitucionais relevantes - Os direitos básicos da pessoa humana e as sucessivas gerações (fases ou dimensões) de direitos (RTJ 164/158, 160-161) - A questão da precedência do direito à preservação do meio ambiente: uma limitação constitucional explícita à atividade econômica (CF, art. 170, VI) - Decisão não referendada - consequente indeferimento do pedido de medida cautelar. A preservação da integridade do meio ambiente: expressão constitucional de um direito fundamental que assiste à generalidade das pessoas." (ADI 3.540-MC, Rel. Min. Celso de Mello, julgamento em 1o-9-2005, Plenário, DJ de 3-2-2006.)
} 
Técnicas editou normas relacionadas direta ou indiretamente a RSS, de observância obrigatória no campo técnico, dentre as quais se podem citar: NBR 7500/2000 - Símbolos de risco e manuseio para o transporte e armazenamento de material; NBR 9191/2008 - Sacos plásticos para acondicionamento de lixo - Requisitos e métodos de ensaio; NBR 10004/2004 - Resíduos sólidos - Classificação; NBR 12235/1992- Armazenamento de resíduos sólidos perigosos; NBR 12807/1993 - Resíduos de serviços de saúde - Terminologia; NBR 12809/1993 - Manuseio de resíduos de serviços de saúde; NBR 12810/1993- Coleta de resíduos de serviços de saúde; NBR 13853/1997 - Coletores para resíduos de serviços de saúde perfurantes ou cortantes; NBR 14652/2000 - Coletor-transportador rodoviário de resíduos de serviços de saúde.

\section{Os Resíduos de Serviços de Saúde (RSS) em Âmbito Estadual e Municipal}

No âmbito estadual o sistema jurídico ambiental de RSS tem como base a Constituição Estadual. Em Sergipe, as normas infraconstitucionais mais importantes são as Leis da Política Estadual de Meio Ambiente (Lei 5.858/2006); da Política Estadual de Resíduos Sólidos (Lei 5.857/2006) e da Política Estadual de Educação Ambiental (Lei 6.882/2010).

Na esfera municipal, o sistema jurídico ambiental tem como base a Lei Orgânica do Município (norma de existência obrigatória), o plano diretor e outras leis municipais específicas para atendimento das normas assim estabelecidas para os resíduos sólidos sem comprometer o meio ambiente.

Em relação à finalidade do sistema vale destacar que, dentro da competência legislativa dos entes federativos (Arts. 24 e 30 da CF), os estados e municípios, ao normatizar sobre RSS, podem aumentar a proteção/conservação ao meio ambiente e à saúde, nunca diminuí-la, sob pena de inconstitucionalidade (princípio da proibição do retrocesso ambiental) ${ }^{12}$ e, consequentemente, ausência de validade da norma estadual ou municipal, mantendo-se assim a integridade deste sistema jurídico, cuja finalidade é a proteção do meio ambiente e da saúde da população, devendo-se priorizar ações preventivas de grande importância como a ação intervencionista de escola como promotora de ação educativa para quebrar paradigmas ${ }^{13}$ educativos frente ao contexto socioambiental e, sobretudo, ao tratar dos aspectos do uso de drogas ilícitas.

\section{Drogas llícitas e a Lei 11.343/2006}

A Lei $11.343 / 2006^{14}$, que revogou a Lei 6.938/1968, institui o Sistema Nacional de Políticas Públicas sobre Drogas (SISNAD) e, dentre outras funções ${ }^{15}$, estabelece atualmente políticas (inclusive de natureza penal) voltadas contra o uso, produção e tráfico ilícito de drogas ${ }^{16}$.

\footnotetext{
12 Para aprofundar, consultar BELCHIOR, 2011, pp. 221-226.

${ }^{13}$ Quebrar o paradigma significa amplamente repensar suas ações enquanto ser e que no paradigma da modernidade na concepção de Santos, pode ser "[...] entendido como um projeto sociocultural muito amplo preenche de contradições e de potencialidades que, aspira a um equilíbrio entre a regulação social e a emancipação social” (2000, p. 348).

${ }^{14}$ Regulamentada pelo Decreto 5.912/2006.

${ }^{15}$ Institui o Sistema Nacional de Políticas Públicas sobre Drogas - SISNAD; prescreve medidas para prevenção do uso indevido, atenção e reinserção social de usuários e dependentes de drogas; estabelece normas para repressão à produção não autorizada e ao tráfico ilícito de drogas; define crimes e dá outras providências.

${ }^{16}$ O Brasil é signatário de três convenções internacionais sobre controle de drogas: Convenção Única sobre Entorpecentes, 1961 (emendada em 1972); Convenção sobre Substâncias Psicotrópicas, 1971; Convenção Contra o Tráfico llícito de Entorpecentes e Substâncias Psicotrópicas, 1988.
} 
O conceito estrito de drogas ${ }^{17}$ é apresentado por norma explicativa da referida Lei, prevista no parágrafo único do artigo 10 "[...] Para fins desta Lei, consideram-se como drogas as substâncias ou os produtos capazes de causar dependência, assim especificados em lei ou relacionados em listas atualizadas periodicamente pelo Poder Executivo da União".

Na Portaria 344/1998 ${ }^{18}$, da SVS/MS, esta definição acima está atrelada ao conceito mais específico de drogas entorpecentes ou psicotrópicas, também chamadas de psicoativas (este último mais utilizado na atualidade). Vale ressaltar que no Brasil o termo droga ilícita é relativo, pois está associado à conduta sem autorização ou em desacordo com determinação legal ou regulamentar.

Por sua vez, a ONU (2012), por meio de seu Escritório contra Drogas e Crimes, classifica a drogas psicotrópicas em três categorias principais: perturbadoras (maconha, cogumelos, LCD, entre outras), depressoras (álcool, opiáceos, solventes e outras) e estimulantes (Cocaína, Ecstasy, anfetaminas, tabaco, entre outras) que são provocadoras de alterações à saúde do sujeito enquanto cidadão brasileiro.

Entre os tipos penais mais importantes na Lei $11.343 / 2006$ estão os que penalizam a conduta do usuário (art. 28) e os relacionados ao tráfico (art. 33 e seguintes), normas penais em branco heterogêneas que se valem da Portaria SVS/MS 344/98 para complementar o preceito primário destas normas penais incriminadoras, estabelecendo assim o limite entre condutas ilícitas e lícitas pertinentes às drogas psicoativas.

Como observado acima, o uso de drogas ilícitas para consumo próprio ainda é criminalizado no Brasil, embora se trate de infração sui generis, considerando-se que seu preceito secundário apresenta penas principais restritivas de direito e não penas privativas de liberdade e/ou multa, fugindo assim do padrão de utilização destas como substitutivas no sistema jurídico pena (artigo 44 do CPB).

O tráfico é considerado equiparado a crime hediondo, submetendo-se assim, o agente condenado a um tratamento mais rigoroso do jus puniendi estatal, tal como a fixação do regime inicial como fechado e a progressão de $2 / 5$ ou 3/5 dependendo da reincidência do agente (Lei 8.072/1990).

Em relação à destinação das drogas ilícitas apreendidas, o artigo 32 da Lei 11.343/2006 traz como única opção a incineração, ressaltando-se que sua finalidade não esgota as possibilidades ambientalmente corretas de destinação final de resíduos do uso de drogas ilícitas, vez que esta norma tem como finalidade a destruição da droga apreendida e não o seu descarte ambientalmente correto após o uso (embora aquela devesse observar esta).

Além disso, desde a década de 1970, a incineração e outras espécies de tratamento térmico de resíduos constituem-se em tema preocupante, considerando a possibilidade de lançamento de toxinas (dioxinas e furanos) e metais no meio ambiente (KREITH, 1994, p. 7.14-7.17; TAMMEMAGI, 1999, p. 155-

\footnotetext{
17 Segundo a OMS, drogas, em sentido lato, é qualquer substância não produzida pelo organismo que altere seu funcionamento. Disponível em: <http://www.who.int/substanceabuse/terminology/ wholexicon/en/>. Acesso em 31 mar. 2012.

${ }^{18}$ A lista de substâncias Entorpecentes, Psicotrópicas, Precursoras e Outras sob Controle Especial, constantes do anexo I da referida Portaria já foi atualizada mais de 30 vezes entre 2008 e 2011, sendo a última alteração efetivada pela RDC 36/2011.
} 
159), razão pela qual, tal atividade ainda não está totalmente liberada para uso no Brasil de acordo com o Decreto $7.404 / 2010^{19}$, embora esta restrição seja direcionada para resíduos sólidos urbanos.

Segundo dados divulgados pelo Observatório Brasileiro de Informações sobre Drogas (OBID), referentes a levantamento domiciliar sobre o uso de drogas psicotrópicas no Brasil entre os anos de 2001 e 2005, observa-se que, mesmo excluindo-se o consumo de tabaco e álcool, é alto o percentual de indivíduos que utilizam drogas psicoativas no país, conforme Tabela 1.

Tabela 1: Levantamento domiciliar sobre o uso de drogas psicotrópicas no Brasil em 2001 e 2005 (em \%).

\begin{tabular}{|l|l|l|l|l|l|l|}
\hline \multirow{2}{*}{ Drogas } & \multicolumn{3}{|c|}{ Período de tempo } \\
\cline { 2 - 7 } & \multicolumn{2}{|c|}{ Uso na vida } & \multicolumn{2}{c|}{ Uso no ano } & \multicolumn{2}{c|}{ Uso no mês } \\
\cline { 2 - 8 } & $\mathbf{2 0 0 1}$ & $\mathbf{2 0 0 5}$ & $\mathbf{2 0 0 1}$ & $\mathbf{2 0 0 5}$ & $\mathbf{2 0 0 1}$ & $\mathbf{2 0 0 5}$ \\
\hline Qualquer droga & 19,4 & 22,8 & 4,6 & 10,3 & 2,5 & 4,5 \\
Maconha & 6,9 & 8,8 & 1,0 & 2,6 & 0,6 & 1,9 \\
Cocaína & 2,3 & 2,9 & 0,4 & 0,7 & 0,2 & 0,4 \\
Crack & 0,4 & 0,7 & 0,1 & 0,1 & 0,0 & 0,1 \\
Heroína & 0,1 & 0,09 & 0,0 & 0,0 & 0,0 & 0,0 \\
Alucinógenos & 0,6 & 1,1 & 0,0 & 0,3 & 0,0 & 0,2 \\
Solventes & 5,8 & 6,1 & 0,8 & 1,2 & 0,2 & 0,4 \\
Opiáceos & 1,4 & 1,3 & 0,6 & 0,5 & 0,2 & 0,3 \\
Benzodiazepínicos & 3,3 & 5,6 & 1,3 & 2,1 & 0,8 & 1,3 \\
Estimulantes & 1,5 & 3,2 & 0,3 & 0,7 & 0,1 & 0,3 \\
Barbitúricos & 0,5 & 0,7 & 0,1 & 0,2 & 0,1 & 0,1 \\
\hline
\end{tabular}

Fonte: Ministério da Justiça/SENAD/OBID ${ }^{20}$.

É importante ressaltar que de 2005 para 2012, o consumo de crack aumentou bastante na população brasileira (UNITED NATIONS, 2011, p. 111), estando os dados acima desatualizados em relação a esta droga ilícita, derivada da cocaína.

Sendo o descarte de resíduos proporcional ao manuseio e uso de qualquer produto, estes dados acima, consequentemente, demonstram que o descarte de resíduos oriundos do uso destas drogas ilícitas é relevante o suficiente para justificar a preocupação com seu o potencial de impactar o meio ambiente e a saúde pública.

Nesse sentido, Daughton (2011, p. 60-61) identifica que até meados da década de 2000 houve a exclusão das drogas ilícitas dos estudos dos impactos de medicamentos no meio ambiente apesar de que as drogas ilícitas terem como característica comum "um altíssimo potencial para efeitos biológicos em humanos e outros organismos [...] drogas ilícitas são usadas mundialmente em enorme quantidade. Entretanto, essa magnitude é desconhecida é pode apenas ser superficialmente estimada ${ }^{21 " \prime}$ (tradução nossa).

Verifica-se até hoje em todo o mundo, mesmo em locais onde foram priorizados os investimentos em políticas e ações de combate às drogas ilícitas, como os Estados Unidos, por exemplo, a persistência de

\footnotetext{
19 “Consoante ainda o Decreto 7.404/2010, observa-se que a recuperação energética de RSU, excepcionado o aproveitamento energético de gases gerados em aterros sanitários, somente será possível depois que tal técnica for disciplinada em ato conjunto específico entre o Ministério do Meio Ambiente, Minas e Energia e Cidades (art. 37), haja vista a polêmica que tal tema ainda causa atualmente, tendo de um lado grandes conglomerados econômicos que defendem sua implantação e, de outro, ambientalistas, associações de catadores e outras instituições que questionam a ausência de segurança em função, dentre outras razões, da possibilidade de emissão de dioxinas e furanos, violando-se com isso a Convenção de Estocolmo de 2001, ratificada pelo Brasil em 2005, através do Decreto 5.472/2005" (COSTA, 2011, p. 62).

${ }^{20}$ Disponível em:<http://www.obid.senad.gov.br/portais/OBID/index.php>. Acesso em: 01 abr. 2012.

21 "Until the mid-2000s, the emerging study of pharmaceuticals in the environment (PiE) inexplicably excluded from consideration one major aspect - the contributions to overall environmental loadings by the so-called illicit drugs. A structurally diverse group of chemical agents uniformly possessing extremely high potential for biological effects in humans and non-target organisms alike, illicit drugs are used in enormous quantities worldwide. However, the actual magnitude of illicit drugs is unknown and can only be roughly estimated".
} 
número considerável de usuários destas e isto não pode ser ignorado. Desta forma, faz-se necessário o estabelecimento de políticas governamentais de redução de danos em relação a estes usuários já que o temor da repressão acaba sendo um obstáculo para a adoção do descarte ambientalmente correto ${ }^{22}$.

Segundo Friedman e Jarlais (1995) a política de redução de danos é importante porque:

Se o uso de drogas, e mais especificamente o seu uso injetável, provoca danos para os usuários e seu entorno, e uma vez que as tentativas de impedir o uso de drogas vêm mostrando se muito falhas, nada mais lógico do que desenvolver programas que tenham como objetivo reduzir os danos causados por essas substâncias. (p.4).

Bueno e Mesquita (1995, p. 11-13) registram a tentativa de implementação de modelos de políticas de redução de danos do município de Santos-SP em 1989 e 1991, em função do aumento, na década de 1980, de casos de AIDS no grupo de usuários de drogas injetáveis por compartilhamento de seringas (UDI), consistindo basicamente em campanhas de desinfecção das seringas com hipoclorito de sódio e na busca da possibilidade de distribuição/trocas de seringas entre os UDI.

Tais políticas de redução de danos devem ser estimuladas, entre outros motivos, como alternativas para se evitar os impactos ambientais e na saúde do descarte incorreto das drogas ilícitas.

\section{Uso de Drogas Ilícitas e Poluição}

A utilização de drogas ilícitas gera resíduos que podem impactar negativamente o meio ambiente, afetando a saúde ${ }^{23}$, a segurança e o bem estar da população. Referindo-se apenas às drogas lícitas, Alvarenga e Nicoletti (2010) expõe que o descarte incorreto de drogas por pessoas físicas é um problema que extrapola as fronteiras de nosso país, porque

em Londres, foi evidenciado por $80 \%$ dos entrevistados reconheceram que a disposição final de medicamentos é um problema, entretanto não necessariamente ambiental, e a maioria dos medicamentos indesejáveis é descartada pelo sistema de lixo e esgoto doméstico (ALVARENGA; NICOLETTI, 2010, p. 35).

A identificação de drogas ilícitas nos recursos naturais, tais como a cocaína e a heroína, está sendo utilizada como critério para se verificar a difusão do uso destas drogas em uma dada localidade através da análise do esgoto público ${ }^{24}$, funcionando como uma ferramenta de rastreamento (DAUGHTON, 2011, p. 72 e 83) denominada de FEUDS (Forensic Epidemiology Using Drugs in Sewage).

Desta forma, segundo Daughton (2011, p. 60-61), o potencial de contaminação do meio ambiente por drogas ilícitas através de uma variedade de formas não difere substancialmente das drogas lícitas

\footnotetext{
22 "Para muitos usuários de drogas, o risco de sofrer algum tipo de penalidade criminal por posse de seringas contendo resíduo de droga parece favorecer o rápido descarte do material usado em condições longe das ideais em termos de biossegurança, ou seja, em locais públicos, banheiros, latas de lixo e outros". (ALBUQUERQUE, 2000)

${ }^{23}$ É importante ressaltar que segundo Ferreira $(1995$, p.318) a preocupação da população com os RSS tem aumentado após o advento da AIDS

24 "We have approached the task of quantifying the diffusion of illicit drug use in the community differently. Among the various measures available to track drug abuse the analysis of waste water plants (WWPs) can represent one of the most reliable source of data. Indeed, WWPs analysis has been increasingly used in recent years to better understand the diffusion of illicit drug use [9-15]. Furthermore, the so-called sewage epidemiology has recently gained the interest of the European Monitoring Centre for Drugs and Drug Addiction [16]. While several studies have developed and validated methods for drug detection in waste water, none of these evaluations - to the best of our knowledge - included a longitudinal evaluation of an entire city. In this perspective this approach to directly estimates the burden of illicit drug use could be complementary or even alternative to capturerecapture designs". (Mari et al), 2009, p. 88-89).
} 
utilizadas na medicina ${ }^{25}$. Embora o parâmetro mais correto e preciso para se avaliar estes impactos fosse o do descarte de medicamentos lícitos no meio ambiente, a legislação brasileira é lacunosa também neste aspecto, como observado acima, de forma que será utilizada a normatização para RSS como parâmetro para a identificação do risco ${ }^{26}$ decorrente do descarte incorreto de resíduos do uso de drogas, verificando-se que, dependendo de suas características, podem se classificar como perigosos e não perigosos (LPNRS e NBR 10.004/2004).

A Resolução 358/2005 do CONAMA apresenta classificação de RSS em cinco grupos: A (agentes biológicos infectantes), subdivididos em cinco grupos (A1 a A5); B (químicos que podem causar risco à saúde pública ou ao meio ambiente); C (radioativos); D (comuns em relação aos equiparados aos resíduos sólidos domiciliares); E (perfurocortantes e similares). Esta classificação define como deve ser o procedimento de gerenciamento destes resíduos em cada uma destas classes. Para os resíduos sólidos de saúde de classe C, devem ser observadas ainda as normas da Comissão Nacional de Energia Nuclear (CNEN), tal como a norma NE- 6.05 .

Segundo Shneider et al (2004, p. 30) os RSS categorizados como agentes biológicos infectantes (classe A) são os que apresentam risco mais evidente para o meio ambiente e a saúde humana "[...] pela presença de consideráveis densidades e variedades de microorganismos infecciosos nos resíduos", quando comparados com a quantidade insignificante produzida de resíduos das classes $\mathrm{B}$ e $\mathrm{C}$ em ambiente hospitalar. O manejo deficiente de RSS também pode ter impactos negativos ao meio ambiente e à saúde da população quando dispostos incorretamente, podendo atingir o ser humano por inalação, ingestão ou injeção (SHNEIDER, et All 2004, p. 31)

No que tange ao preparo e uso de uso de drogas ilícitas, a contaminação com agentes biológicos (classe A) é preocupante, principalmente quando associada a restos de instrumentos perfurocortantes (classe E) utilizados para a preparação e o manuseio da droga ilícita, fato esse que amplia esse quantitativo, ao se verificar que, em 2009, quase metade dos usuários de drogas ilícitas injetáveis no Brasil estavam contaminados com a AIDS e a Hepatite $C^{27}$. No entanto não se pode olvidar da contaminação oriunda de agentes químicos, principalmente quando dispostos nos recursos hídricos ou no solo sem maiores cuidados ${ }^{28}$.

Tendo como base a Resolução CONAMA 358/2005 (RSS), apresentamos tabela dos principais fatores de poluição do solo, da água e do ar, além do risco direto à saúde humana, que podem ser associados com o descarte indevido de produtos decorrentes do preparo e uso de drogas ilícitas, conforme Tabela 2.

\footnotetext{
25 "The potential for illicit drugs to enter the environment via a wide array of pathways should not differ much from that of pharmaceuticals used in the practice of medicine". (DAUGHTON, 2011, p. 60-61).

26 "Os resíduos de serviços de saúde são considerados perigosos e requerem maiores cuidados não pela sua quantidade excessiva dentre os resíduos produzidos pela população urbana, e sim, devido ao seu grande potencial de risco, devido ao fato de conter substâncias extremamente nocivas ao meio ambiente e aos seres vivos em geral" (MARTINS, 2004, p.31).

27 "In some countries, the prevalence of HIV among injecting drug users is extremely high, such as in Estonia (72\%), Argentina (50\%) and Brazil (48\%) [... ] and around half of all injecting drug users are infected with the Hepatitis C virus (HCV)". (Word Drug Report, 2011, p. 30).

28 “Além dos danos decorrentes da disposição inadequada dos [RSS] à água superficial e/ou subterrânea, ao ar e ao solo..." (SHNEIDER, et al 2004, p. 33).
} 
Tabela 2: Relação entre a Resolução CONAMA 358/2005 e o descarte de resíduos de drogas ilícitas.

\begin{tabular}{|c|l|l|l|}
\hline Classe & Tipo & Correlação com preparo e uso de drogas ilícitas & Destino ambientalmente adequado \\
\hline A & $\begin{array}{l}\text { Infectantes } \\
\text { biológicos }\end{array}$ & $\begin{array}{l}\text { Características de maior virulência ou } \\
\text { concentração de agentes biológicos infectantes, } \\
\text { podendo estar presente no manuseio e uso de } \\
\text { drogas. }\end{array}$ & $\begin{array}{l}\text { Aterro sanitário licenciado ou local devidamente } \\
\text { licenciado para disposição final de resíduos dos } \\
\text { serviços de saúde após tratamento prévio } \\
\text { podem ser reciclados ou reutilizados }\end{array}$ \\
\hline B & $\begin{array}{l}\text { Infectantes } \\
\text { químicos }\end{array}$ & $\begin{array}{l}\text { Características de inflamabilidade, corrosividade, } \\
\text { reatividade e toxicidade, podendo estar presente } \\
\text { no manuseio e uso de drogas. }\end{array}$ & $\begin{array}{l}\text { Quando perigosos devem ser dispostos em } \\
\text { aterro de resíduos perigosos. Quando não } \\
\text { perigosos podem ser dispostos em aterro } \\
\text { licenciado e, quando no estado líquido, lançados } \\
\text { na rede de esgoto desde que atendam aos } \\
\text { padrões normativos. }\end{array}$ \\
\hline C & Radioativos & $\begin{array}{l}\text { Embora extremamente poluentes não tem } \\
\text { relação com o uso de drogas ilícitas. }\end{array}$ & $\begin{array}{l}\text { Não podem ser descartados até atingirem o } \\
\text { tempo de decaimento. }\end{array}$ \\
\hline D & Comuns & $\begin{array}{l}\text { Não apresentem risco biológico, químico ou } \\
\text { radiológico, podendo ser equiparados aos } \\
\text { resíduos domiciliares }\end{array}$ & $\begin{array}{l}\text { Aterro sanitário de RSU licenciado e podem ser } \\
\text { reutilizados ou reciclados. }\end{array}$ \\
\hline E & $\begin{array}{l}\text { Perfurocor- } \\
\text { tantes e si- } \\
\text { milares }\end{array}$ & $\begin{array}{l}\text { Materiais perfurocortantes ou escarificantes, tais } \\
\text { como: agulhas, ampolas de vidro, tubos, } \\
\text { utensílios de vidro quebrados e outros similares } \\
\text { infectados com agentes biológicos ou químicos, } \\
\text { sendo bastante incidentes no manuseio e uso de } \\
\text { drogas. }\end{array}$ & $\begin{array}{l}\text { Tratamento específico de acordo com a } \\
\text { contaminação química, biológica ou radiológica e } \\
\text { devem ser apresentados para coleta } \\
\text { acondicionados em coletores estanques, rígidos e } \\
\text { hígidos, resistentes à ruptura, à punctura, ao } \\
\text { corte ou à escarificação. }\end{array}$ \\
\hline
\end{tabular}

Fonte: Baseado na CONAMA 358/2005.

\section{CONCLUSÕES}

A disposição incorreta de resíduos do preparo e uso de drogas ilícitas pode impactar o meio ambiente e a saúde da população, devendo ser adotados pelo poder público e pela sociedade mecanismos para alterar esta realidade.

A estreita cooperação entre os poderes públicos (federal, estadual e municipal) e a sociedade civil orientada e consciente sobre a gravidade dos resíduos sólidos no meio ambiente por meio da ação intervencionista, educativa, preventiva apresenta um lastro fecundo de contribuições para a compreensão dos problemas de saúde pública de modo que ao direcionar seus atos, atitudes, comportamentos frente ao não usar drogas e assim desencadear um (re) significar do seu modo de vida social, sobretudo ao reconhecer os riscos danosos a sua vida com punições que variam de acordo com as leis vigentes.

Nesse sentido, uma alerta deve ser feito à sociedade civil quanto ao descarte de drogas no meio ambiente repensando os limites e desafios dessa ação por via da formação humana, essa entendida como uma que "[...] transcende o ensino que pretende uma mera atualização científica, pedagógica e didática e se transforma na possibilidade de criar espaços de participação, reflexão e formação" (IMBERNÓN, 2004, p. 15) de modo a atingir diretamente ao meio ambiente com ações exequíveis baseando-se em estratégias "[...] de pensamento, de percepção, de estímulos e centra-se na tomada de decisões para processar, sistematizar e comunicar a informação" (IMBERNÓN, 2004, p. 41).

Portanto, devemos (res)situar todas as informações fragmentárias recebidas dentro de um contexto sócio-cultural mais amplo, mostrar as relações, as mediações, os momentos da história; as condições sociais numa relação dialógica e porque não entender as normativas quanto ao descarte correto de resíduos ou

\footnotetext{
${ }^{29}$ Com exceção do grupo A4, que dispensam tratamento prévio.
} 
melhor, porque não "[...] fazer desabrochar e desenvolver tal subjetividade para compreensão do espírito crítico e para a libertação" (JAPIASSU, 1975, p. 149) ao propormos um sistema social e educativo reflexivo, critico, analítico e coerente de ideias nos quais a prática individual e coletiva encontra lugar para as determinações de sentidos para a vida com saúde.

\section{REFERÊNCIAS}

ALBUQUEQUE, K. C.. Fatores de Risco para a infecção pelo HIV entre Usuários de Drogas Injetáveis nas "Ruas" da cidade do Rio de Janeiro. Dissertação (Mestrado em Saúde Pública) - Escola Nacional de Saúde Pública, Rio de Janeiro, 2000.

ALVARENGA, L. S. V.; NICOLETTI, M. A.. Descarte doméstico de medicamentos e algumas considerações sobre o impacto ambiental. São Paulo: Revista Saúde, 2010.

ARENDT, H.. A condição humana. 10 ed. Rio de Janeiro: Forence Universitária, 2001.

BELCHIOR, G. P. N.. Hermenêutica jurídica ambiental. São Paulo: Saraiva, 2011.

BUENO, R. C.; MESQUITA, F.. O trabalho entre usuários de drogas injetáveis em santos. In: Boletim da Associação Brasileira Interdisciplinar de AIDS - ABIA, n.27, p.11-13, 1995.

CARVALHO, A. C. L.. Comentários à lei penal ambiental: parte geral e parte especial (artigo por artigo). Curitiba: Juruá, 2011.

CHEREMISINOFF, N. P.. Handbook of solid waste management and waste minimization Technologies. Burlington: Elsevier's Science, 2003.

COSTA, S. L.. Gestão integrada de resíduos sólidos urbanos: aspectos jurídicos e ambientais. Aracaju: Evocati, 2011.

DALLARI, S. G.. Direito Sanitário. In: Direito Sanitário e Saúde Pública. Brasília: Legislação de Saúde, 2003.

DAUGHTON, C. G.. Illicit Drugs: contaminants in the environment and utility in forensic epidemiology. Reviews of Environmental Contamination and Toxicology, n.210, p.59110, 2011

FAZENDA, I.. O que é interdisciplinaridade. São Paulo: Cortez, 2008.

FERREIRA, J. A.. Resíduos sólidos e lixo hospitalar: uma discussão ética. Cad. Saúde Públ., Rio de Janeiro, v.11, n.2, p.314-320, 1995.
FREIRE, P.. Conscientização: teoria e prática da libertação: uma introdução ao pensamento de Paulo Freire. São Paulo: Cortez \& Moraes, 1979.

FRIEDMAN, S. R.; JARLAIS, D. D.. Prevenção da AIDS entre os usuários de drogas injetáveis nos países em desenvolvimento. In: Boletim da Associação Brasileira Interdisciplinar de AIDS-ABIA, n.27, p.2-3, 1995.

IMBERNÓN, F.. Formação Docente e profissional: formar-se para a mudança e a incerteza. 4 ed. São Paulo: Cortez, 2004

JAPIASSU, H.. O mito da neutralidade científica. Rio de Janeiro: Imago, 1975.

KREITH, F.; TCHOBANOGLOUS, G.. Handbook of solid waste management. New York: McGraw-Hill, 1994.

MARI, F. et al.. Cocaine and heroin in waste water plants: A 1-year study in the city of Florence, Italy. Forensic Science International, n.189, p.88-92, 2009.

MARTINS, F. L.. Gerenciamento de resíduos sólidos de serviços de saúde: análise comparativa das legislações federais. Dissertação (Mestrado em Sistemas de Gestão) Universidade Federal de Fluminense, Niterói, 2004.

ORGANIZAÇÃO DAS NAÇÕES UNIDAS. Drogas: você conhece o risco? Brasília: Escritório das Nações Unidas contra Drogas e Crime. 2012

SANTOS, B. S.. Pela mão de Alice: o social e o político na pósmodernidade. São Paulo: Cortez, 2000.

SHNEIDER, V. E. et al.. Manual de gerenciamento de serviços de saúde. 2 Ed. Caxias do Sul: Educs, 2004.

TAMMEMAGI, H.. The waste crisis: landfills, incinerators, and the search for a sustainable future. New York: Oxford University Press, 1999.

UNITED NATIONS. World Drug Report: 2011. New York: Office on Drugs and Crime, 2011. 